УДК 622.276

\title{
УЧЕТ ПАРАМЕТРА АНИЗОТРОПИИ ПРОНИЦАЕМОСТИ В ГЕОЛОГО-ГИДРОДИНАМИЧЕСКИХ МОДЕЛЯХ КАРБОНАТНЫХ ОБЪЕКТОВ (НА ПРИМЕРЕ ГАГАРИНСКОГО МЕСТОРОЖДЕНИЯ)
}

\author{
Менгалиев Александр Генрихович1, \\ mengaliev.alexandr@gmail.com
}

\author{
Мартюшев Дмитрий Александрович², \\ martyushevd@inbox.ru \\ 1 Филиал ООО «ЛУкОЙЛ-Инжиниринг» «ПермНИПИнефть» в г. Перми, \\ Россия, 614000, г. Пермь, ул. Советской Армии, 29. \\ 2 Пермский национальный исследовательский политехнический университет, \\ Россия, 614990, г. Пермь, пр. Комсомольский, 29.
}

\begin{abstract}
Актуальность работы. Значительная доля разрабатываемых нефртяных активов, приуроченных к карбонатным сложнопостроенным объектам, заметно возросла как на территории России, так и в Пермском крае. Достоверное знание параметров трещинно-порового типа коллектора позволяет уточнить действующие геолого-гидродинамические модели, подобрать рациональную систему разработки, регулировать процессы разработки и обеспечить для данного пласта оптимальнье геолого-технические мероприятия. При построении и адаптации геолого-гидродинамических моделей нефртяных месторождений, особенно относящихся к сложнопостроенным карбонатным коллекторам, важное значение имеет знание как горизонтальной, так и вертикальной проницаемости (параметра анизотропии). При создании геолого-гидродинамических моделей карбонатных объектов месторождений Пермского края зачастую вертикальную проницаемость принимают равной нулю, хотя это далеко не так. Определение вертикальной проницаемости (параметра анизотропии), ее динамика при изменении пластового и забойного давлений и использование в геолого-гидродинамических моделях является актуальной задачей, которая позволит повысить качество и достоверность использования цисрровых моделей для расчета и прогнозирования процесса добычи нефрти.

Цель: совершенствование геолого-гидродинамических моделей с учетом использования показателя анизотропии проницаемости.

Объект: карбонатная фаменская залежь Гагаринского месторождения.

Методы: обработка данных геолого-промысловых исследований; использование гидродинамического симулятора Tempest версии 8.3.1 компании Roxar.

Результаты. По предложенной в статье методике определения параметра анизотропии обработаны 252 исследования, проведенные на добывающих и нагнетательных скважинах фраменской залежи Гагаринского месторождения. Для каждой литолого-фациальной зоны построена зависимость показателя анизотропии проницаемости от забойного давления. Для прогнозирования и оценки эффрективности применяемых геолого-технических мероприятий и технологических показателей разработки авторами статьи модифицирована геолого-гидродинамическая модель с учетом полученных зависимостей об изменении параметра анизотропии. С помощью модифицированной гидродинамической модели удалось значительно улучшить адаптацию как по добывающим, так и по нагнетательным скважинам. Таким образом, повысилось качество и достоверность цифровой модели фраменской залежи Гагаринского месторождения для расчетов и прогнозирования процесса добычи нефоти.
\end{abstract}

\section{Ключевые слова:}

Гидродинамические исследования скважин, вертикальная проницаемость, горизонтальная проницаемость, литолого-фрациальные зоны, модиффицированная гидродинамическая модель.

\section{Введение}

Значительная доля разрабатываемых нефтяных активов, приуроченных к карбонатным сложнопостроенным объектам, заметно возросла как на территории России, так и в Пермском крае. Карбонатные сложнопостроенные коллектора характеризуются различными типами пустотности (поры, трещины, каверны), значительной неоднородностью, перетоками флюидов между типами пустот, а также различием между латеральной и вертикальной проницаемостью, данные факторы в значительной мере влияют на продуктивность и производительность добывающих скважин и в целом на коэффициент нефтеизвлечения [1-4]. Достоверное знание параметров трещинно-порового типа коллектора позволяет уточнить действующие геологогидродинамических модели (ГГДМ), подобрать раци- ональную систему разработки, регулировать процессы разработки и обеспечить для данного пласта оптимальные геолого-технические мероприятия (ГТМ) [5-8].

При построении и адаптации ГГДМ нефтяных месторождений, особенно относящихся к сложнопостроенным карбонатным коллекторам, важное значение имеет знание как горизонтальной, так и вертикальной проницаемости (параметра анизотропии). При создании ГГДМ карбонатных объектов месторождений Пермского края зачастую вертикальную проницаемость принимают равной нулю, хотя это далеко не так $[9,10]$. Даже в самых низкопроницаемых пластах аргиллитов, по которым в лабораторных исследованиях проницаемость практически была равна нулю, может быть развита трещиноватость, а если 
существует еще и линзовидность напластования, то по всему резервуару вертикальную проницаемость принимать равной нулю неверно [11]. Особое значение знание вертикальной проницаемости в условиях сложнопостроенного карбонатного коллектора играет при активной роли пластовых вод [12-14]. Добыча нефти может быть высокой на протяжении некоторого периода времени, но затем снизится при появлении конуса подошвенной воды, который часто образуется при форсированной и нерациональной выработке запасов и необоснованных технологических режимах добывающих скважин. Процесс образования конусов протекает намного интенсивнее в трещинных коллекторах, имеющих вертикальные трещины, так как именно они простираются далеко вниз в подстилающие пласты, образуя пути для создания конусов воды. Таким образом, определение вертикальной проницаемости (параметра анизотропии) и использование ее в ГГДМ являются актуальными задачами, которые позволят повысить качество и достоверность использования цифровых моделей для расчета и прогнозирования процесса добычи нефти.

\section{Методы определения параметра анизотропии (вертикальной проницаемости)}

На сегодняшний день существует несколько промысловых методов, с помощью которых можно оценить вертикальную проницаемость, но каждый из этих методов имеет свои преимущества и недостатки, которые представлены в таблице.

Параметр анизотропии проницаемости в карбонатных коллекторах может быть определен различными геофизическими, промысловыми и гидродинамическими исследованиями скважин и пластов (ГДИ). Изучение кернового материала и геофизические исследования не могут дать точных знаний об особенностях

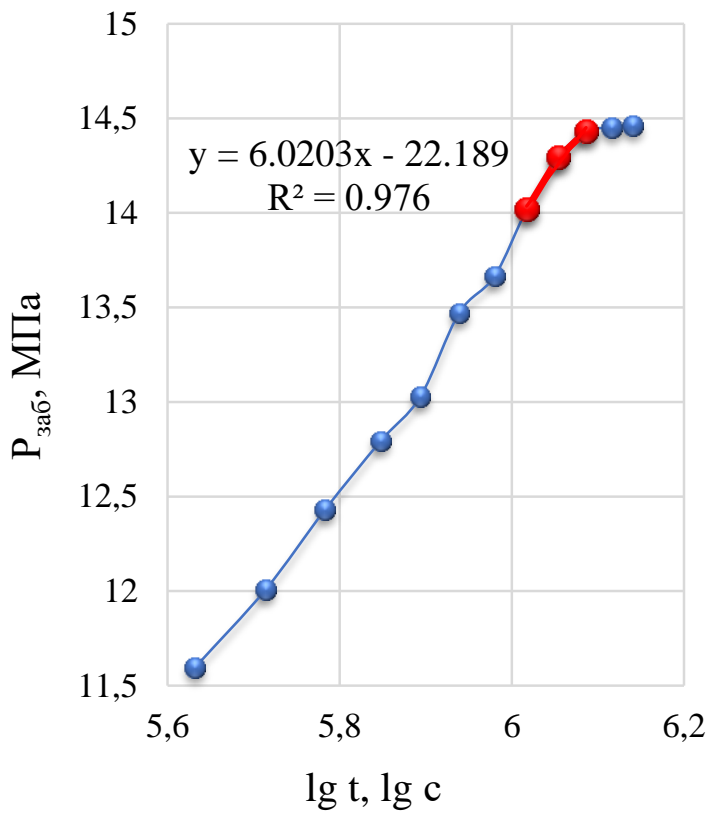

a/a

пласта в связи с особенностями самих исследований. Наиболее разработанными методами определения параметра анизотропии проницаемости являются методы гидропрослушивания и трассирование меченых веществ, однако они достаточно длительные и дорогостоящие $[15,16]$. Метод трассирующих индикаторов может быть надежно реализован на поздней стадии разработки месторождения при интенсивном обводнении продукции. Особое внимание следует уделять интерпретации данных гидродинамических исследований скважин (КВД или КВУ) как наиболее распространенному методу контроля за разработкой месторождений, позволяющему решить огромный круг производственных и научных задач $[17,18]$.

Определение параметра анизотропии проницаемости по данным гидродинамических исследований скважин

В статье [19] коллективом авторов изложена методика определения вертикальной проницаемости и параметра анизотропии проницаемости. Актуальность данных расчетов очевидна, поскольку, с одной стороны, повышает информативность исследований скважин методом восстановления давления, с другой стороны, позволяет получить весьма ценную информацию об анизотропии пласта без затрат на проведение специальных исследований. Ниже представлена методика определения параметра анизотропии на примере скважины № 405 фаменской залежи Гагаринского месторождения.

1. Исходная кривая восстановления давления (КВД) перестраивается в координатах « $\mathrm{P}_{\text {заб }}(\mathrm{t})-\lg (\mathrm{t}) »$ (рис. $1, a$ ). Рассматривается конечная часть КВД выделяется конечный участок и определяется уклон $\beta$, для текущего примера $\beta=6,0203 \mathrm{MПа} / \mathrm{lg}$ c.

2. Также КВД строится в координатах « $\left.\mathrm{P}_{\text {заб }}(\mathrm{t})-1 / \mathrm{t}^{0,5}\right\rangle$ (рис. 1, б).

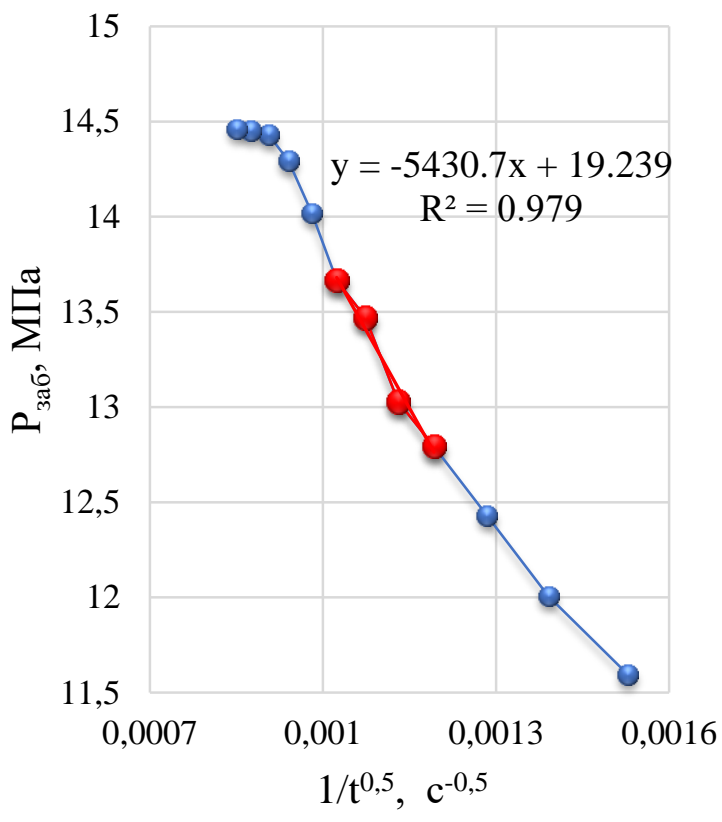

$\sigma / b$

Pис. 1. Кривая восстановления давления, перестроенная в координатах: a) « $P_{\text {заб }}(t)-\lg (t) » ;$ б) « $P_{\text {заб }}(t)-1 / t^{0,5} 》$

Fig. 1. Pressure recovery curve rebuilt in coordinates: a) « $\left.P_{\text {заб }}(t)-\lg (t) » ; b\right)$ « $P_{\text {заб }}(t)-1 / t^{0,5} 》$ 
Таблица. Методы определения параметра анизотропии (вертикальной проницаемости)

Table. $\quad$ Methods for determining the anisotropy parameter (vertical permeability)

\begin{tabular}{|c|c|c|c|}
\hline $\begin{array}{l}\text { Метод } \\
\text { Method }\end{array}$ & $\begin{array}{c}\text { Способ определения } \\
\text { Method of determination }\end{array}$ & $\begin{array}{c}\text { Преимущества } \\
\text { Advantages }\end{array}$ & $\begin{array}{c}\text { Недостатки } \\
\text { Disadvantages }\end{array}$ \\
\hline \multirow{3}{*}{$\begin{array}{l}\text { Промыслово- } \\
\text { геофизические } \\
\text { исследования } \\
\text { Geophysical } \\
\text { surveys }\end{array}$} & $\begin{array}{l}\text { Боковой каротаж скани- } \\
\text { рующий } \\
\text { Side logging scan }\end{array}$ & $\begin{array}{l}\text { Позволяет судить о наличии в разрезе верти- } \\
\text { кальных и субвертикальных трещин при } \\
\text { значении показателя анизотропии пород } \\
\text { более } 1,3 \\
\text { Allows you to judge the presence in the section } \\
\text { of vertical and sub-vertical fractures with a value } \\
\text { of anisotropy of rocks more than } 1,3\end{array}$ & $\begin{array}{l}\text { Определяется не сам показатель анизо- } \\
\text { тропии проницаемости, а лишь анизо- } \\
\text { тропия электропроводности пластов, } \\
\text { однако такая оценка возможна при отно- } \\
\text { сительно низкоомном разрезе (водона- } \\
\text { сыщенные коллекторы } 11-100 \text { Ом*м, } \\
\text { нефтенасыщенные - 20-500 Ом*м) } \\
\text { It is not the permeability anisotropy index } \\
\text { itself that is determined, but only the anisot- } \\
\text { ropy of the electrical conductivity of the } \\
\text { layers, but such an assessment is possible } \\
\text { with a relatively low-ohm section (water- } \\
\text { saturated collectors } 11-100 \text { Ohm*m, oil- } \\
\text { saturated - 20-500 Ohm*m) }\end{array}$ \\
\hline & $\begin{array}{l}\text { Волновые методы (вол- } \\
\text { новой акустический } \\
\text { каротаж и др.) } \\
\text { Wave methods (wave } \\
\text { acoustic logging, etc.) }\end{array}$ & $\begin{array}{l}\text { Определение физико-механических свойств } \\
\text { пород (ФМС), позволяющих судить о нали- } \\
\text { чии трещиноватости. В обсаженных скважи- } \\
\text { нах путем сравнительных измерений пара- } \\
\text { метров ФМС, волны Стоунли, коэффициента } \\
\text { анизотропии до и после гидроразрыва пласта } \\
\text { (ГРП) определяются интервалы ГРП. } \\
\text { Determination of physico-mechanical properties } \\
\text { of rocks, which allow judging the presence of } \\
\text { fracture. In cased wells, comparative measure- } \\
\text { ments of parameters of physicomechanical } \\
\text { properties, Stoneley waves, anisotropy coeffi- } \\
\text { cients before and after hydraulic fracturing, } \\
\text { determine fracturing intervals. }\end{array}$ & $\begin{array}{l}\text { Определяется не сам показатель анизо- } \\
\text { тропии проницаемости, а лишь акустиче- } \\
\text { ская анизотропия пород по интервально- } \\
\text { му времени быстрой и медленной попе- } \\
\text { речных волн. } \\
\text { It is not the permeability anisotropy index } \\
\text { itself that is determined, but only the acous- } \\
\text { tic anisotropy of rocks by the interval time } \\
\text { of fast and slow transverse waves. }\end{array}$ \\
\hline & \multicolumn{3}{|c|}{$\begin{array}{l}\text { Вывод: определение целого ряда различных параметров, характерных для ГИС, но оценка на качественном уровне. } \\
\text { Привязка к скважине - локальность определения. } \\
\text { Conclusion: definition of a number of different parameters characteristic of well logging, but the assessment at a qualitative } \\
\text { level. Binding to the well - locality of determination. }\end{array}$} \\
\hline $\begin{array}{l}\text { Исследования } \\
\text { керна } \\
\text { Core studies }\end{array}$ & $\begin{array}{l}\text { Изучение ориентирован- } \\
\text { ного керна } \\
\text { Oriented core study }\end{array}$ & $\begin{array}{l}\text { Изучение проницаемости вдоль направлений } \\
\text { X, Y, Z. Возможность создания различных } \\
\text { термобарических условий и характера насы- } \\
\text { щения. Численное определение значения } \\
\text { искомого параметра. } \\
\text { Study of permeability along the X, Y, Z direc- } \\
\text { tions. The possibility of creating different tem- } \\
\text { perature and pressure conditions and the nature } \\
\text { of saturation. Numerical determination of the } \\
\text { value of the desired parameter. }\end{array}$ & $\begin{array}{l}\text { Дороговизна и редкость отбора ориенти- } \\
\text { рованного керна, соответственно, невоз- } \\
\text { можность исследования для скважины, в } \\
\text { которой в период бурения не отобран } \\
\text { керн. Привязка к скважине - локальность } \\
\text { определения. Иногда невозможность } \\
\text { воссоздать пластовые условия. } \\
\text { High cost and rarity of the selection of } \\
\text { oriented core, respectively, the impossibility } \\
\text { of research for the well, in which the core } \\
\text { was not selected during the drilling period. } \\
\text { Binding to the well - locality of determina- } \\
\text { tion. Sometimes the inability to recreate } \\
\text { reservoir conditions. }\end{array}$ \\
\hline $\begin{array}{l}\text { Гидродинами- } \\
\text { ческие исследо- } \\
\text { вания скважин } \\
\text { Well test }\end{array}$ & $\begin{array}{l}\text { Интерпретация кривой } \\
\text { восстановления давления } \\
\text { (уровня) } \\
\text { Interpretation of the pres- } \\
\text { sure recovery curve (level) }\end{array}$ & $\begin{array}{l}\text { Снятие КВД (КВУ) входит в стандартный } \\
\text { комплекс исследований по контролю за раз- } \\
\text { работкой месторождений. Отсутствие необ- } \\
\text { ходимости в специальных дорогих приборах. } \\
\text { Численное определение значения искомого } \\
\text { параметра. Охват по площади зоны дрениро- } \\
\text { вания. Сравнительно высокая скорость обра- } \\
\text { ботки. } \\
\text { Removal of the pressure recovery curve (level } \\
\text { recovery curve) is a part of the standard research } \\
\text { complex for field development control. No need } \\
\text { for special expensive devices. Numerical deter- } \\
\text { mination of the value of the desired parameter. } \\
\text { Coverage area of the drainage zone. Relatively } \\
\text { high processing speed. }\end{array}$ & $\begin{array}{l}\text { Желательно наличие ТМС и отсутствие } \\
\text { возмущений от соседних скважин. } \\
\text { It is desirable to have a telemetry system } \\
\text { and the absence of disturbances from neigh- } \\
\text { boring wells. }\end{array}$ \\
\hline $\begin{array}{l}\text { Специальные } \\
\text { методы ГдИ } \\
\text { Special methods } \\
\text { of well testing }\end{array}$ & $\begin{array}{l}\text { Гидропрослушивание } \\
\text { пластов и трассирование } \\
\text { меченых веществ } \\
\text { Hydraulic interception of } \\
\text { layers and tracing of la- } \\
\text { beled substances }\end{array}$ & $\begin{array}{l}\text { Наиболее полно разработанные способы, } \\
\text { большой охват исследованиями. Численное } \\
\text { определение значения искомого параметра. } \\
\text { The most fully developed methods, large re- } \\
\text { search coverage. Numerical determination of the } \\
\text { value of the desired parameter. }\end{array}$ & $\begin{array}{l}\text { Дороговизна. Длительность исследова- } \\
\text { ний. Для трассирования необходима } \\
\text { большая обводненность продукции. } \\
\text { High cost. Duration of research. Tracing } \\
\text { requires a high water cut. }\end{array}$ \\
\hline
\end{tabular}


На КВД, построенной в координатах $\left\langle\mathrm{P}_{\text {заб }}(\mathrm{t})-1 / \mathrm{t}^{0,5} »\right.$, выделяется прямолинейный участок так, чтобы время, соответствующее его окончанию, было меньше, чем время, соответствующее началу прямолинейного участка в координатах « $\mathrm{P}_{\text {заб}}(\mathrm{t})-\lg (\mathrm{t}) »$, и определяется уклон участка $\sigma$. В данном примере обозначен участок с параметрами: $\mathrm{t}=954540 \mathrm{c}, \sigma=5430,7 \mathrm{MПа} \cdot \mathrm{c}^{-0,5}$.

1. Зная вскрытую (работающую) толщину $\mathrm{h}_{\text {вс }}$, величины $\sigma$ и $\beta$ и координаты последней точки прямой, построенной в координатах « $\mathrm{P}_{\text {заб }}(\mathrm{t})-1 / \mathrm{t}^{0,5} »$, определяют общую толщину пласта:

$$
\begin{gathered}
\mathrm{h}=\frac{\mathrm{h}_{\mathrm{BC}}}{\left(1-\frac{\beta \cdot \sqrt{1,5 \cdot \mathrm{t}}}{2,09 \cdot \sigma}\right)}=\frac{18,3}{\left(1-\frac{6,0203 \cdot \sqrt{1,5 \cdot 954540}}{2,09 \cdot 5430,7}\right)} \\
=50,09 \mathrm{M} .
\end{gathered}
$$

2. Вычисляется вертикальная проницаемость $\left(\mathrm{K}_{\mathrm{B}}\right)$ :

$$
\begin{gathered}
\mathrm{K}_{\mathrm{B}}=\frac{0,229 \cdot \mathrm{m} \cdot \mu \cdot \mathrm{h} \cdot \beta}{\mathrm{P}_{\text {пл }} \cdot \sigma}= \\
=\frac{0,229 \cdot 0,11 \cdot 3,4 \cdot 10^{-3} \cdot 50,09 \cdot 6,0203}{14,52 \cdot 10^{6} \cdot 5430,7}=327,56 \text { мД. }
\end{gathered}
$$

где $\mathrm{m}$ - пористость, д. ед.; $\mathrm{P}_{\text {пл }}$ - текущее пластовое давление, МПа; $\mu$ - вязкость флюида в условиях пласта, мПа $\cdot$ с.

3. Вычислив вертикальную проницаемость, рассчитывают вертикальную пьезопроводность:

$$
\begin{gathered}
\alpha_{\text {в }}=\frac{\mathrm{P}_{\text {пл }} \cdot \mathrm{K}_{\text {в }}}{\mu \cdot \mathrm{m}}=\frac{14,52 \cdot 10^{6} \cdot 327,56 \cdot 10^{-15}}{3,4 \cdot 10^{-3} \cdot 0,11}= \\
=0,0127 \mathrm{M}^{2} / \mathrm{c}
\end{gathered}
$$

4. Зная значение вертикальной пьезопроводности, вычисляют горизонтальную проницаемость $\left(\mathrm{K}_{\mathrm{r}}\right)$ :

$$
\begin{gathered}
\mathrm{K}_{\mathrm{r}}=\frac{\mathrm{Q} \cdot \mathrm{T}_{\text {пл }} \cdot \mu}{\pi \cdot \sigma \cdot \sqrt{3,3 \alpha_{\text {в }}}}= \\
=\frac{45,95 \cdot 10^{-5} \cdot 306 \cdot 3,4 \cdot 10^{-3}}{3,14 \cdot 5430,7 \cdot 10^{6} \cdot \sqrt{3,3 \cdot 0,01272}}=136,78 \text { мД, }
\end{gathered}
$$

где Q - дебит скважины перед исследованием, м³/c; $\mathrm{T}_{\text {пл }}$ - пластовая температура, $\mathrm{K}$.

5. Находится параметр анизотропии:

$$
v=\frac{K_{\mathrm{B}}}{\mathrm{K}_{\Gamma}}=\frac{327,56 \cdot 10^{-15}}{136,78 \cdot 10^{-15}}=2,39 \text { д. ед. }
$$

По данной методике обработаны 252 исследования, проведенные на добывающих и нагнетательных скважинах фаменской залежи Гагаринского месторождения. Стоит отметить, что карбонатная залежь нефти в фаменских отложениях Гагаринского месторождения характеризуется двойной пустотностью и имеет следующую геологическую особенность: по площади распространения залежи установлено чередование коллекторов разной емкости для одних и тех же стратиграфических горизонтов, обусловленное условиями седиментации [20-23]. Лучшими фильтрационно-емкостными свойствами (ФЕС) обладает часть залежи в виде рифового гребня, в более низкорельефные участки в процессе седиментации сносил- ся микритовый материал, который заполнял естественные трещины, ухудшая фильтрационноемкостные свойства горных пород (рис. 2). Для каждой литолого-фациальной зоны построена зависимость показателя анизотропии проницаемости от забойного давления (рис. 3). Полученные зависимости, представленные на рис. 3, могут быть использованы для прогнозирования параметра анизотропии проницаемости в каждой литолого-фациальной зоне, что повлияет на подбор оптимального технологического режима работы скважин и на выбор геологотехнических мероприятий [24-27].

Для прогнозирования и оценки эффективности применяемых геолого-технических мероприятий и технологических показателей разработки авторами статьи модифицирована ГГДМ с учетом полученных зависимостей об изменении параметра анизотропии проницаемости. Модифицированная ГГДМ по сравнению с базовой моделью, которая не учитывает показатель анизотропии (вертикальную проницаемость), поможет достовернее и качественнее оценить технологические показатели разработки и режимы работы скважин после проведения ГТМ.

\section{Совершенствование геолого-гидродинамической} модели с учетом изменения показателя анизотропии

Существует множество способов учета трещиноватости в гидродинамических моделях. Первый, который является наиболее трудоемким, но при этом физичным, - это создание модели двойной среды [28]. Очевидным преимуществом использования такой ГГДМ является учет сложного строения пустотного пространства при многофазной фильтрации пластовых флюидов. Однако процесс построения модели и ее использования связан со значительными трудностями, такими как неоднозначность определения параметров трещинной среды и утяжеление модели с замедлением скорости расчетов, т. к. будет распределение фильтрационно-емкостных свойств между двумя пустотностями, а также перетоки между ними. Поэтому на практике встретить такие модели можно довольно редко. Другой способ основан на использовании в ГГДМ слоев с низкой пористостью и высокой проницаемостью, например, в районе скважин [29]. Применяют также не соседние соединения, при которых флюид практически мгновенно может перенестись от одной точки пласта до другой. Косвенно смоделировать фильтрацию в трещинно-поровом коллекторе можно с помощью кривых ОФП [30, 31]. Встречаются на практике методы учета изменения проницаемости коллектора в зависимости от динамики пластового давления [32]. Один из подобных методов, который дает удовлетворительные показатели при рациональных временных затратах на модификации, выбран для учета трещинной составляющей пустотного пространства фаменской залежи Гагаринского месторождения. Моделирование производилось в гидродинамическом симуляторе Tempest версии 8.3.1 компании Roxar. 


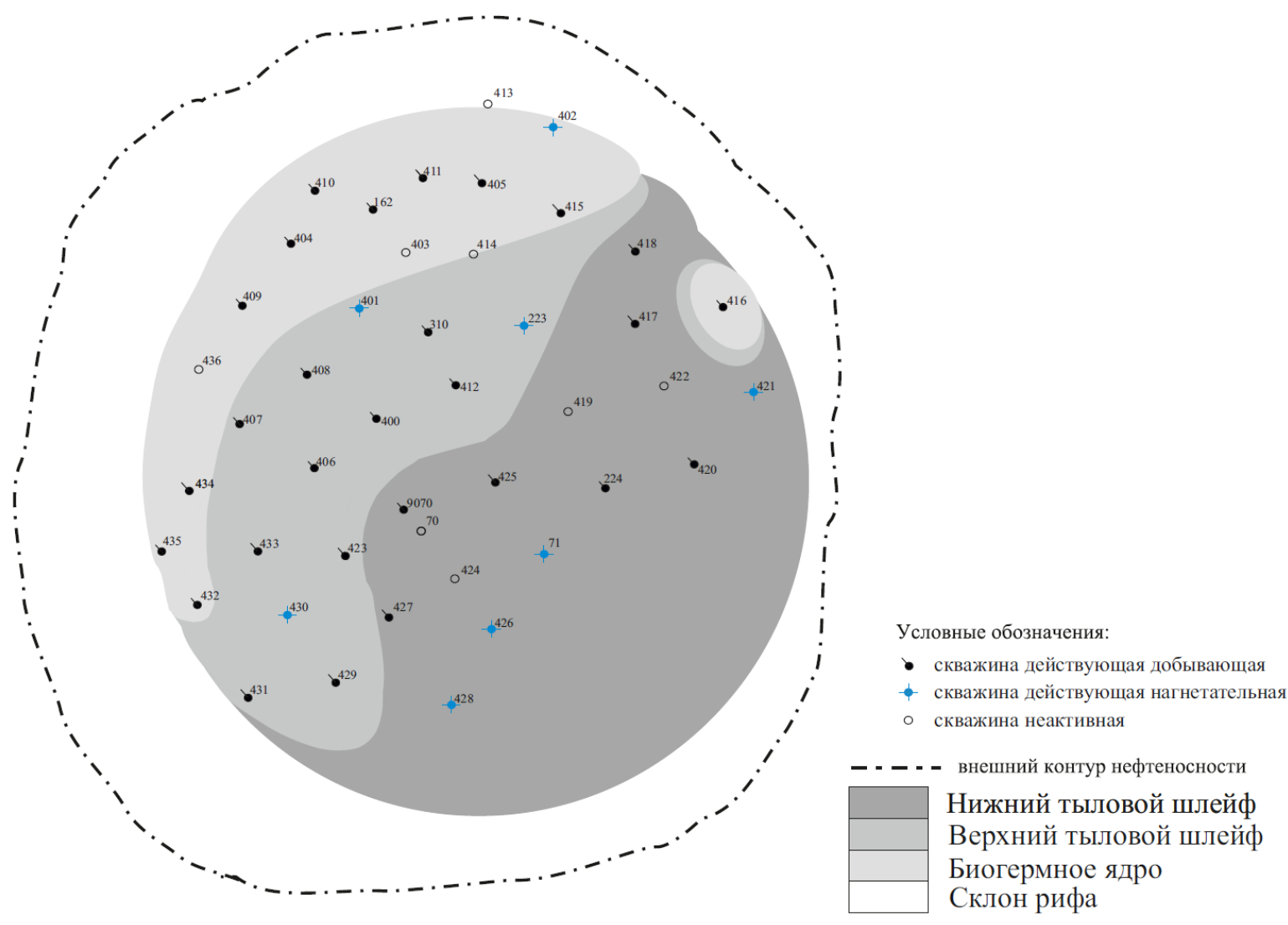

Рис. 2 Литолого-фациальная карта фаменских отложений Гагаринского месторождения

Fig. 2. Lithofacies map of the Famennian deposits of the Gagarinsky field

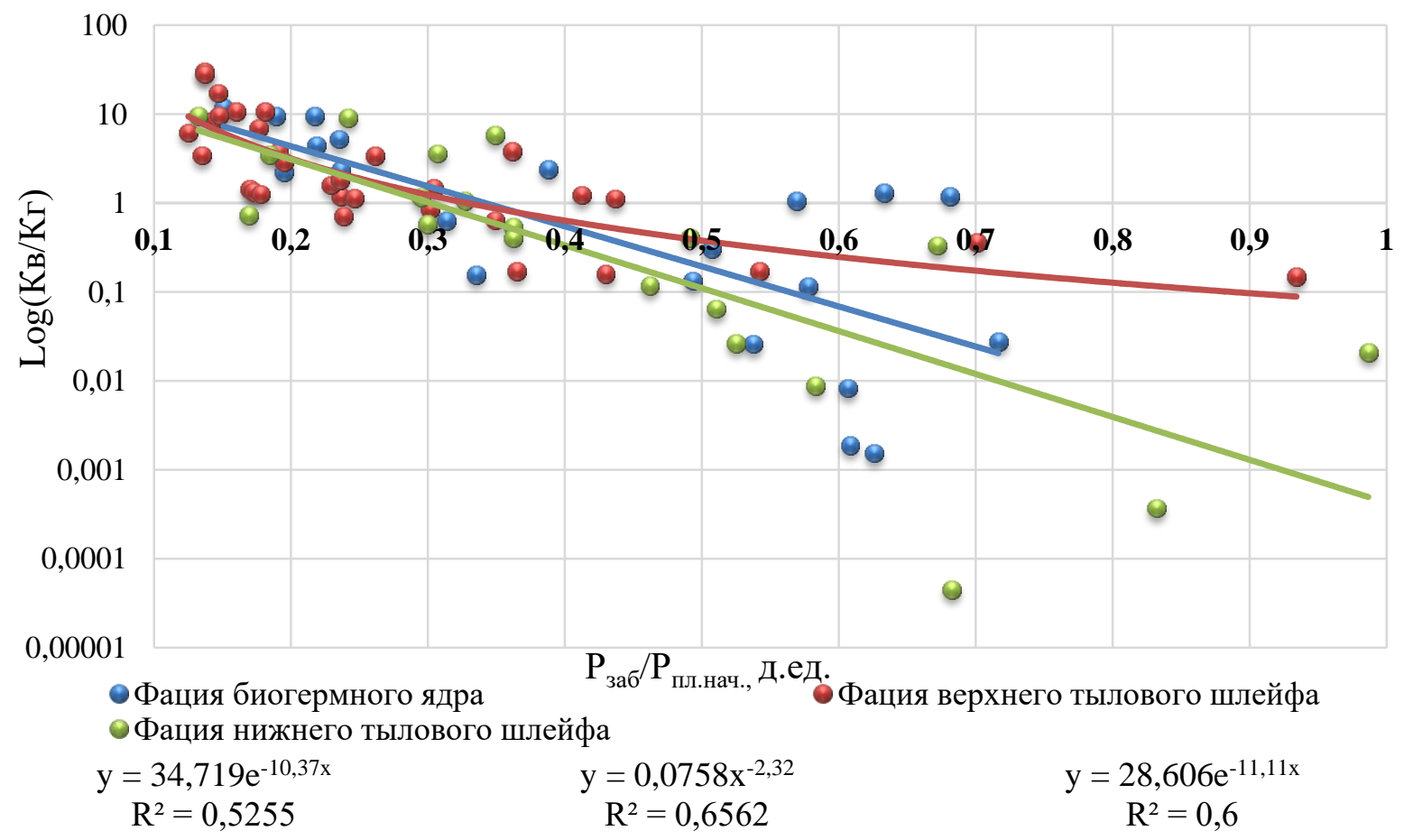

Pис. 3. Зависимость показателя анизотропии от забойного давления для каждой литолого-фациальной зоны фаменской залежи Гагаринского месторождения

Fig. 3. Dependence of the anisotropy index on the bottomhole pressure for each lithofacial zone of the Famennian deposit of the Gagarinsky field 
Предварительно вертикальная проницаемость численно настраивалась по результатам интерпретации ГДИ. Далее происходил процесс модификации гидродинамической модели путем поиска множителей проницаемости в несколько этапов:

1. Преобразование полученной зависимости показателя анизотропии от отношения текущего забойного к начальному пластовому давлению в зависимость показателя анизотропии от текущего пластового давления. Зависимость будет иметь примерно такой же вид.

2. Построение зависимость проницаемости от пластового давления при анализе проведенных гидродинамических исследований на неустановившихся режимах. Проницаемость, получаемая при исследованиях, будет равна проницаемости по латерали $\mathrm{K}_{\mathrm{x}}=\mathrm{K}_{\mathrm{y}}$.
3. При достаточно маленьком шаге, например, 5 бар, от атмосферного до пластового давления (выше можно уменьшать дискретность) получаются значения проницаемости по латерали.

4. Горизонтальная проницаемость подставляется в зависимость пункта 1. Получается распределение вертикальной проницаемости от пластового давления.

Принимается, что при начальном пластовом давлении проницаемости не изменены, а при изменении давления в ту или иную сторону увеличиваются либо уменьшаются. Так как распределение проницаемости в зоне каждой скважины может значительно различаться, то для использования необходимы не сами значения проницаемостей, а их множители (при $\mathrm{P}_{\text {пл }}=\mathrm{P}_{\text {пл•нач }}$ множитель равен единице). Проделанные операции представлены на рис. 4.

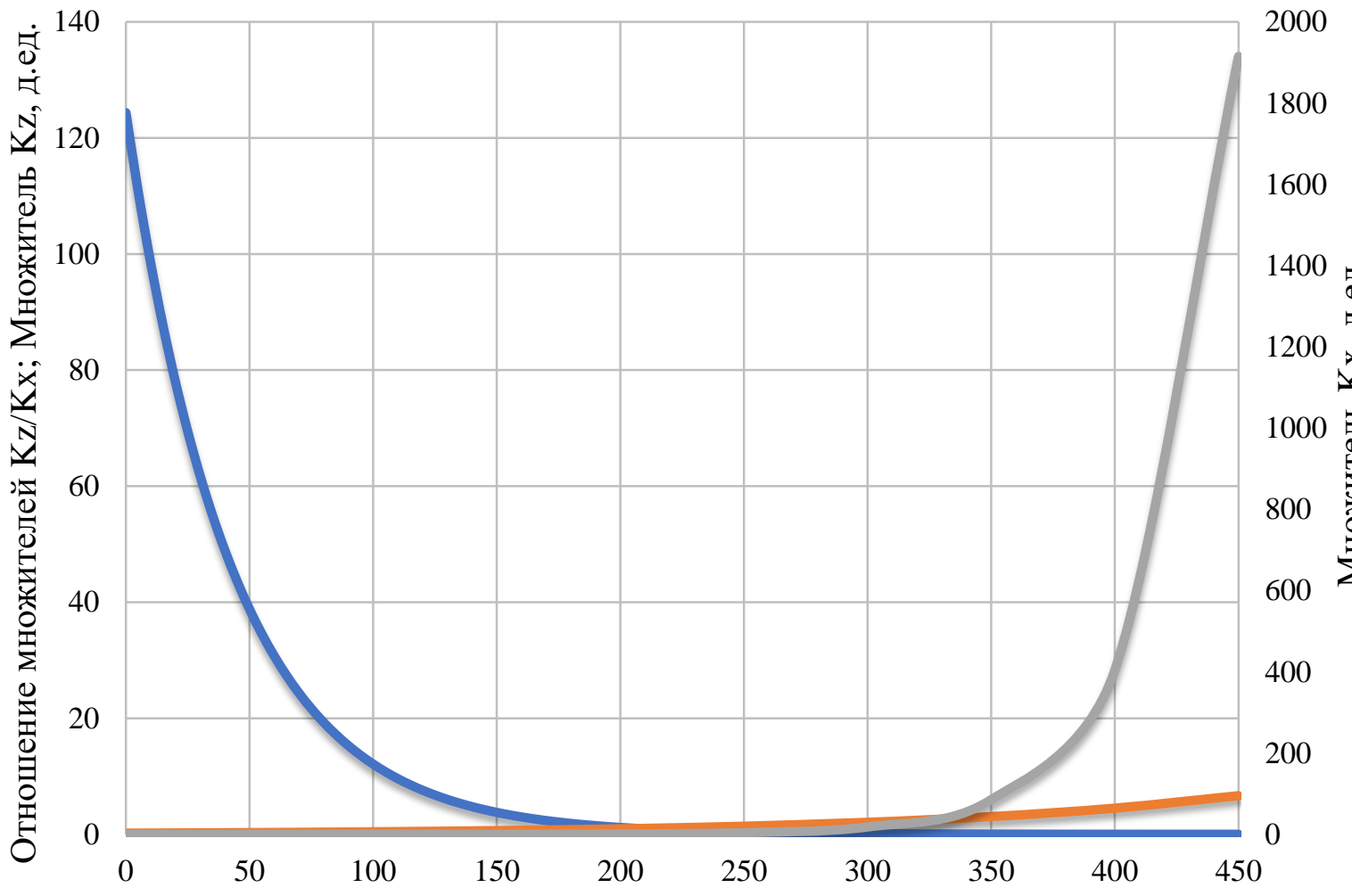

Пластовое давление, бар

Отношение множителей Kz/Kx, д.ед. $\longrightarrow$ Множитель Kz, д.ед. $\longrightarrow$ Множитель Kx, д.ед.

Pис. 4. Зависимость множителей проницаемости от пластового давления для фации верхнего тылового шлейфа

Fig. 4. Dependence of permeability multipliers on reservoir pressure for the facies of the upper rear plume

Анализируя полученные графики, можно прийти к выводу, что при значительном снижении пластового давления роль вертикальной фильтрации выходит на первый план. Данная процедура была выполнена для каждой литолого-фациальной зоны рассматриваемого объекта разработки. Таким образом, имеются зависимости изменения проницаемостей по латерали и вертикали для каждой зоны. В отличии от распространенного способа при помощи ключевого слова KVSP применение ключевых слов KVPX, KVPY и KVPZ дает возможность разнонаправленного распределения изменения проницаемости от давления, что и было сделано. Внешний вид модифицированной геологогидродинамической модели представлен на рис. 5 на примере куба измененных регионов.

При работе с модифицированной моделью получилось улучшить адаптацию как по добывающим, так и по нагнетательным скважинам (рис. 5, 6). 


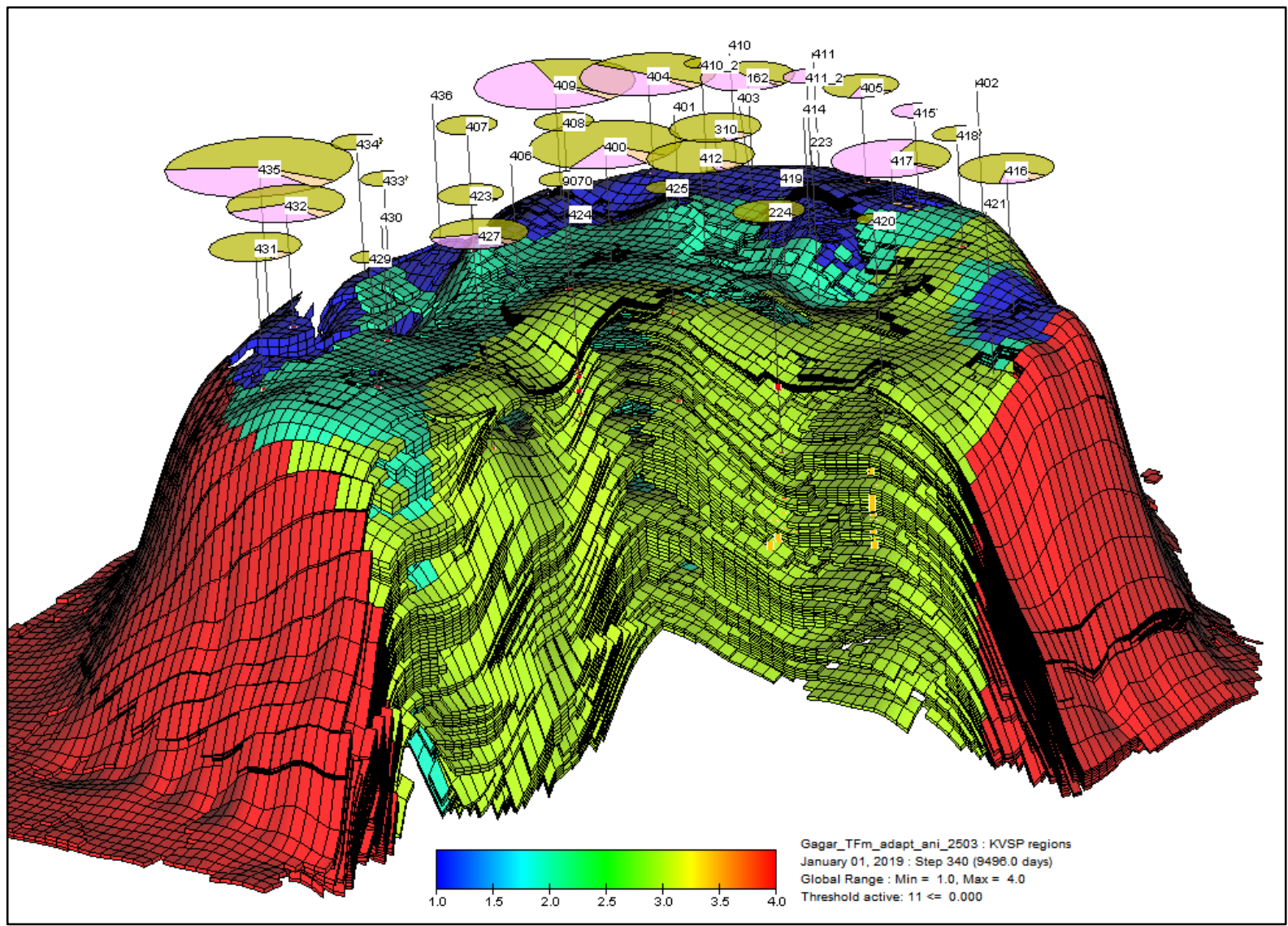

Рис. 4. Внешний вид модифицированной геолого-гидродинамической модели фаменской залежи Гагаринского месторождения

Fig. 4. Appearance of the modified geological and hydrodynamic model of the Famennian deposit of the Gagarinsky field

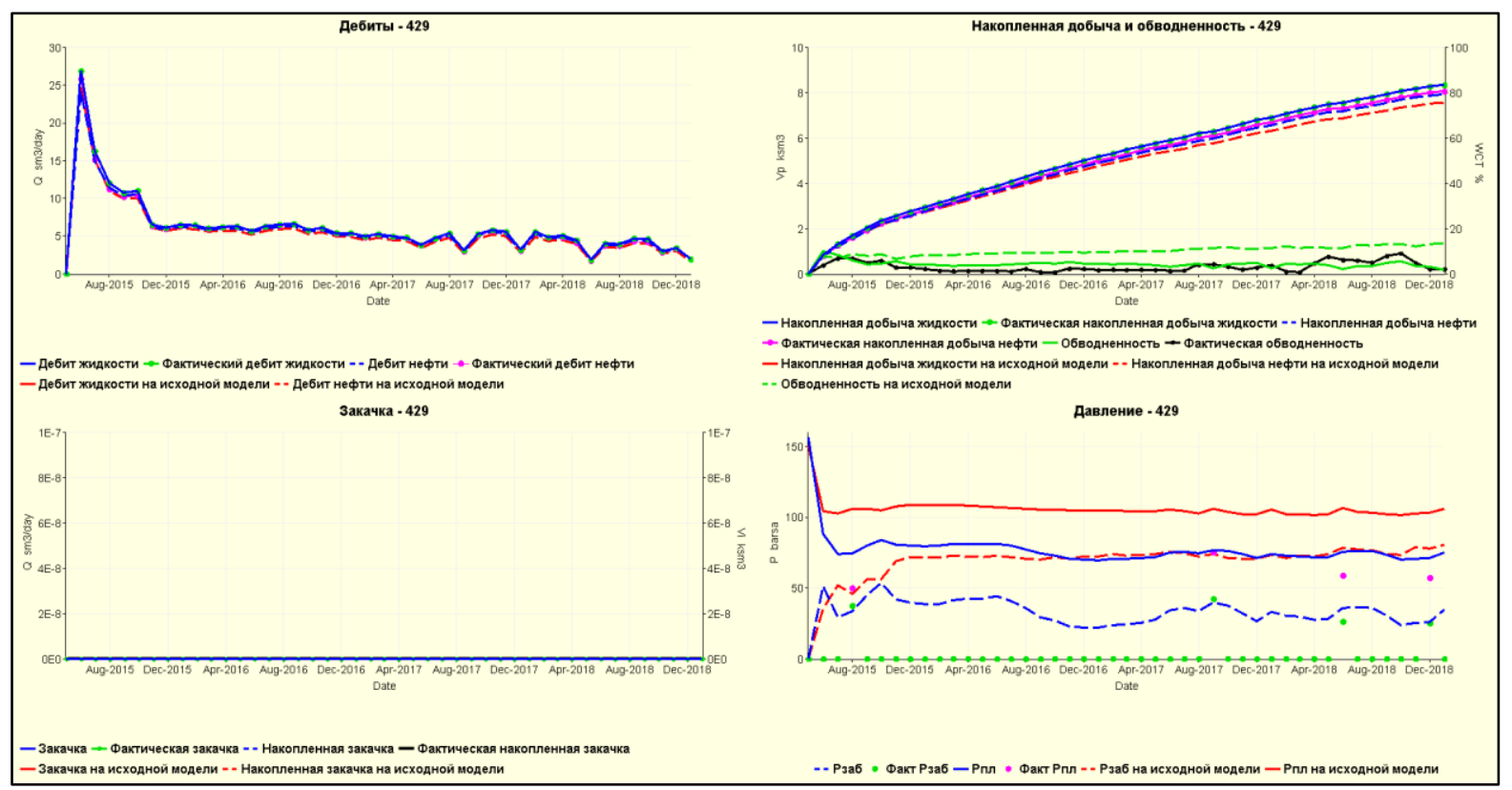

Pис. 5. Сравнение результатов адаптаџии по добывающей скв. 429 на модифицированной и исходной модели Fig. 5. Comparison of the results of adaptation for mining well 429 on the modified and the original model 


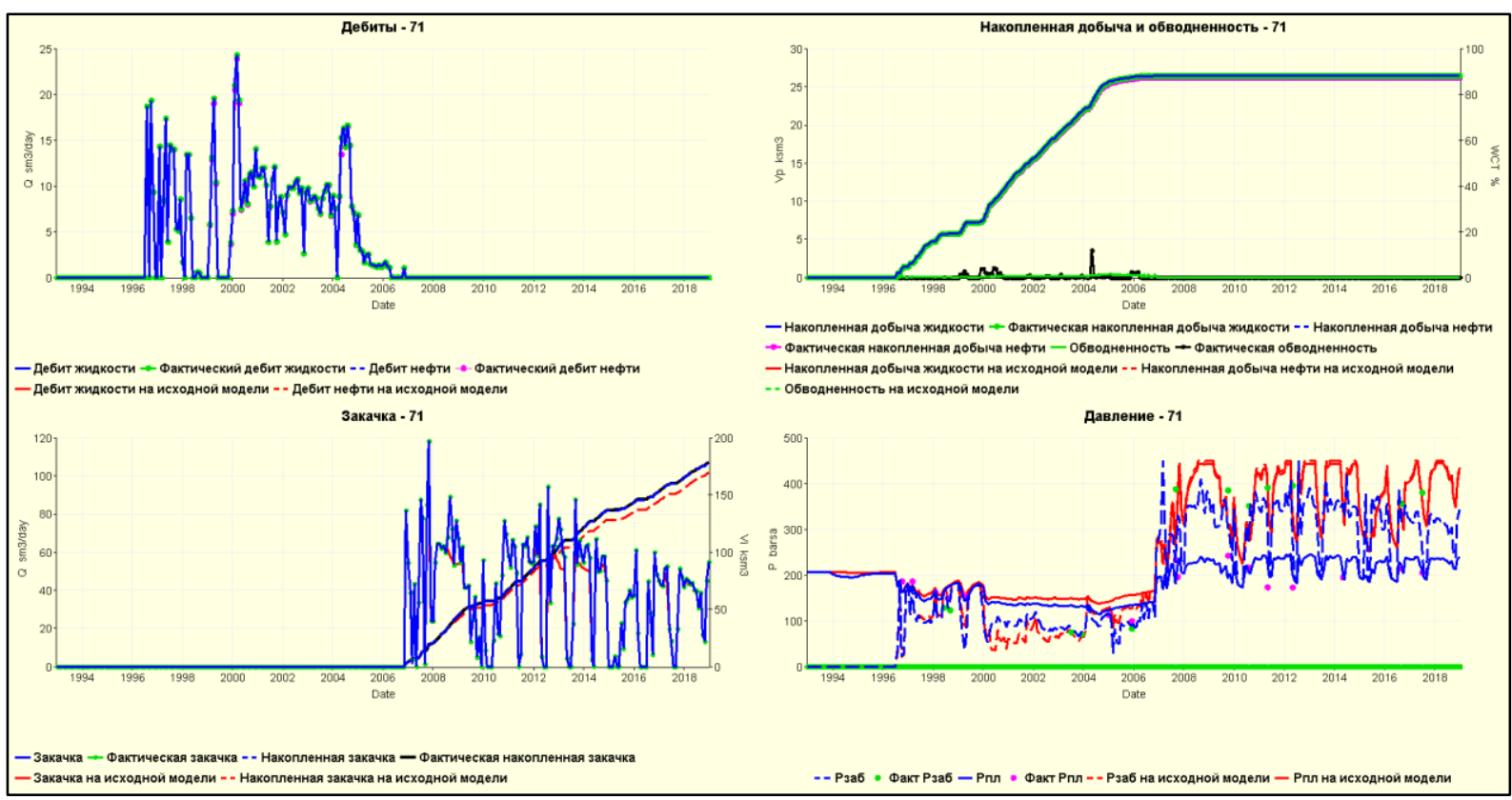

Рис. 6. Сравнение результатов адаптации по нагнетательной скв. 71 на модифицированной и исходной модели

Fig. 6. Comparison of the results of adaptation for injection well 71 on the modified and the original model

Таким образом, проведенные расчеты в модифицированной гидродинамической модели по скв. 429 позволили воссоздать динамику забойного давления, настроить тренд пластового давления и значительно улучшить сходимость параметра обводненности. По скв. 71 удалось добиться необходимой исторической репрессии, а также весь объем закачиваемой жидкости ушел в пласт. На исходной модели этого не получилось и забойное давление находилось на полке в некоторые периоды времени. Моделировался эффект авто-ГРП.

\section{Заключение}

В данной статье рассмотрена актуальная проблема, направленная на определение параметра анизотропии проницаемости (вертикальной проницаемости) и его учет в действующих геолого-гидродинамических моделях (на примере фаменской залежи Гагаринского месторождения). Описан подход, который позволяет оперативно оценить вертикальную и горизонтальную проницаемость, а также параметр анизотропии без проведения специальных дорогостоящих и долговременных исследований, а в рамках регулярных гидродинамических исследований (КВД или КВУ). Для

\section{СПИСОК ЛИТЕРАТУРЫ}

1. Вахитова Г.Р., Галин Н.Н., Гумерова А.С. Анализ заводнения продуктивных пластов при наличии пространственной неоднородности // Сборник научных трудов SWORLD по материалам международной научно-практической конференции. 2011. - Т. 13. - Вып. № 2. - С. 80-90.

2. Huafeng Sun, Sandra Vega, Guo Tao. Analysis of heterogeneity and permeability anisotropy in carbonate rock samples using digital rock physics // Journal of petroleum science and engineering. 2017. - V. 156. - P. 419-429.

3. Байков В.А., Аксаков А.В., Борщук О.С. Математическое моделирование миграции жидкости через флюидоупор по трещинам // Нефтяное хозяйство. - 2018. - № 5. - С. 48-51. каждой литолого-фациальной зоны фаменской залежи Гагаринского месторождения получена зависимость изменения параметра анизотропии проницаемости от забойного давления. Установлено, что значения показателя анизотропии в различных литологофациальных зонах изменяются в широком диапазоне. С помощью полученных зависимостей оценки параметра анизотропии проницаемости была модифицирована действующая геолого-гидродинамическая модель фаменской залежи Гагаринского месторождения. С помощью модифицированной гидродинамической модели удалось значительно улучшить адаптацию как по добывающим, так и по нагнетательным скважинам. Таким образом, удалось повысить качество и достоверность цифровой модели фаменской залежи Гагаринского месторождения для расчетов и прогнозирования процесса добычи нефти. С помощью описанной в статье методики можно оценить изменение параметра анизотропии проницаемости и на других карбонатных объектах месторождений Пермского края и России и в дальнейшем модифицировать существующие геолого-гидродинамические модели.

4. Кадыров Р.И., Закиров Т.Р. 2D фрактальный и мультифрактальный анализ пустотно-пористого пространства карбонатных коллекторов нефти // Нефтяное хозяйство. - 2016. № 11. - C. $72-74$.

5. Мартюшев Д.А. Оценка трещиноватости карбонатных коллекторов вероятностно-статистическими методами // Нефтяное хозяйство. - 2014. - № 4. - С. 51-53.

6. Абдуллин Р.Н., Рахматуллин А.Р. Пример практического применения информации о трещиноватости по данным комплекса ГИС и высокотехнологических методов // Георесурсы. - 2017. - T. 20. - № 3. - C. 261-266.

7. A permeability model for naturally fractured carbonate reservoir / V. Guerriero, S. Mazzoli, A. Iannace, S. Vitale, Ch. Strauss // Marine and petroleum geology. - 2013. - V. 40. - P. 115-134. 
8. Иктисанов В.А., Бобб И.Ф., Ганиев Б.Г. Изучение закономерностей оптимизации забойных давлений для трещиннопоровых коллекторов // Нефтяное хозяйство. - 2017. - № 10. C. 94-97.

9. Henderson N., Pena L. Simulating effects of the permeability anisotropy on formation of viscous fingers during waterflood operations // Journal of petroleum science and engineering. - 2017. V. 153. - P. 178-186.

10. Jackson R.R., Banerjee R. Application of reservoir simulation and history matching methods to MDT vertical interference testing and determination of permeability anisotropy $/ / 8^{\text {th }}$ European Conference on the mathematics of oil recovery. - Freiberg, Germany, 3-6 September 2002. - P. 775-794.

11. Ханипов М.Н., Насыбуллин А.В., Саттаров Р.З. Оценка влияния неоднородности коллектора на эффективность нестационарного заводнения с применением геолого-гидродинамического моделирования // Нефтяное хозяйство. - 2016. - № 7. - С. 30-32.

12. Кудряшова Д.А. Использование вероятно-статистических методов для определения источников обводнения скважинкандидатов для водоизоляционных работ (на примере визейского объекта месторождения пермского края) // Вестник Пермского национального исследовательского политехнического университета. Геология. Нефтегазовое и горное дело. 2018. - T. 17. - № 1. - C. 26-36.

13. Biao Li, Ron C.K. Wong, Sina Heidari. A modified KozenyCarman model for estimating anisotropic permeability of soft mudrocks // Marine and petroleum geology. - 2018. - V. 98. P. 356-368.

14. Experimental study of impact of anisotropy and heterogeneity on gas flow in coal. P. II: Permeability / Yuling Tan, Zhejun Pan, Jishan Liu, Fubao Zhou, Asadul Haque // Fuel. - 2018. - V. 230. P. 397-409.

15. Minory Sato, Takato Takemura, Manabu Takahashi. Development of the permeability anisotropy of submarine sedimentary rocks under true triaxial stresses // International journal of rock mechanics and mining sciences. - 2018. - V. 108. - P. 118-127.

16. Noirot M., Massonnat G., Jourde H. On the use of Wireline Formation testing (WFT) data: 2. Consequences of permeability anisotropy and heterogeneity on the WFT responses inferred flow modeling // Journal of petroleum science and engineering. 2015. - V. 133. - P. 776-784.

17. Цаган-Маджиев Т.Н. Повышение достоверности определения вертикальной проницаемости пласта по данным гидродинамических исследований // Газовая промышленность. - 2012. № 5. - C. 19-23.

18. Wen Zhang, Qin Wang. Permeability anisotropy and gas slippage of shales from the Sichuan Basin in South China // International journal of coal geology. - 2018. - V. 194. - P. 22-32.

19. Оценка анизотропии проницаемости карбонатных коллекторов по кривым восстановления давления / С.С. Черепанов, Д.А. Мартюшев, И.Н. Пономарева, Г.П. Хижняк // Нефтяное хозяйство. - 2013. - № 4. - С. 60-61.

20. Галкин В.И., Пономарева И.Н., Репина В.А. Исследование процесса нефтеизвлечения в коллекторах различного типа пустотности с использованием многомерного статистического анализа // Вестник Пермского национального исследовательского политехнического университета. Геология. Нефтегазовое и горное дело. - 2016. - Т. 15. - № 19. - С. 145-154.
21. Щербенев А.В. Использование вероятно-статистических методов для деления пород на проницаемую и непроницаемую части (на примере терригенных отложений визейского яруса Софьинского месторождения) // Вестник Пермского национального исследовательского политехнического университета. Геология. Нефтегазовое и горное дело. - 2017. - Т. 16. № 1. - C. 14-22

22. Бегма Д.С., Белкина В.А. Литолого-фациальные особенности строения верхнеюрских отложений месторождения Т // Известия Томского политехнического университета. Инжиниринг георесурсов. - 2017. - Т. 328. - № 1. - С. 109-122.

23. Особенности геологического строения и перспективы разработки низкопроницаемых карбонатных коллекторов Подверьюского нефтяного месторождения / Р.С. Хисамов, А.Г. Хабибрахманов, В.Б. Подавалов, Ю.П. Кемаева, Л.М. Миронова // Нефтяное хозяйство. - 2016. - № 11. - С. 84-87.

24. Investigation of the permeability anisotropy of 2D fractured rock masses / Feng Ren, Guowei Ma, Guoyang Fu, Ke Zhang // Engineering geology. -2015 . - V. 196. - P. 171-182.

25. Farrell N.J.C., Healy D., Taylor C.W. Anisotropy of permeability in faulted porous sandstones // Journal of structural geology. 2014. - V. 63. - P. 50-67.

26. Menezes F.F. Anisotropy of volume change and permeability evilution of hard sandstones under triaxial stress conditions // Journal of petroleum science and engineering. - 2019. - V. 174. P. 921-939.

27. The permeability of styolite-bearing limestone / M. Heap, T. Reuschle, P. Baud, F. Renard, G. Lezzi // Journal of structural geology. -2018 . - V. 116. - P. 81-93.

28. Методика гидродинамического моделирования сложнопостроенных карбонатных трещиноватых коллекторов на примере Манчаровского месторождения / А.И. Саяхутдинов, Н.Р. Кондратьева, Д.Ч. Галлямова, Э.В. Карачурина, Е.С. Булатова // Нефтяное хозяйство. - 2014. - № 2. - С. 114-115.

29. Черепанов С.С., Чумаков Г.Н., Галкин С.В. Возможности учета трещиноватости коллекторов при геологогидродинамическом моделировании разработки залежей с заводнением пластов // Нефтепромысловое дело. - 2016. № 8. - C. 5-8.

30. Щипанов А.А. Модификация относительных фазовых проницаемостей как один из подходов к учёту трещиноватости коллекторов при гидродинамическом моделировании // Геология, геофизика и разработка нефтяных и газовых месторождений. 2002. - № 8. - С. 60-66.

31. О связи коэффициентов трещиностойкости и геофизических характеристик горных пород месторождений углеводородов / Ю.А. Кашников, С.Г. Ашихмин, А.Э. Кухтинский, Д.В. Шустов // Записки горного института. - 2020. - Т. 241. - С. 83-90.

32. Аббасов Е.М., Агаева Н.А., Керимова Ш.А. Интегральное моделирование работы газовых скважин с учетом деформируемости коллектора пласта // SOCAR Proceedings. - 2019. № 2. - C. $45-52$.

\section{Информация об авторах}

Менгалиев $\boldsymbol{A . \Gamma . , ~ и н ж е н е р ~ 2 - и ̆ ~ к а т е г о р и и ~ о т д е л а ~ с о з д а н и я ~ и ~ м о н и т о р и н г а ~ г и д р о д и н а м и ч е с к и х ~ м о д е л е и ̆ ~ п р и о р и - ~}$ тетных месторождений филиала ООО «ЛУКОЙЛ-Инжиниринг» «ПермНИПИнефть» в г. Перми.

Мартюшев Д.А., кандидат технических наук, доцент кафедры нефтегазовых технологий Пермского национального исследовательского политехнического университета. 
UDC 622.276

\title{
ACCOUNTING THE PARAMETER OF ANISOTROPY OF PERMEABILITY IN GEOLOGICAL AND HYDRODYNAMIC MODELS OF CARBONATE OBJECTS (ON THE EXAMPLE OF THE GAGARIN DEPOSIT)
}

\author{
Alexander G. Mengaliev1, \\ mengaliev.alexandr@gmail.com \\ Dmitriy A. Martyushev², \\ martyushevd@inbox.ru \\ 1 LLC «LUKOIL-Engineering» «PermNIPIneft» in Perm, \\ 29, Sovetskoy Armii street, Perm, 614000, Russia. \\ 2 Perm National Research Polytechnic University, \\ 29, Komsomolskiy avenue, Perm, 614990, Russia.
}

The relevance of the research. A significant share of the developed oil assets, confined to carbonate complex objects, has increased markedly both in Russia and in the Perm Krai. Reliable knowledge of the parameters of a fracture-porous reservoir type allows selecting a rational development system, controlling development, ensuring optimal geological and technical measures for a given reservoir, clarifies the existing geological and hydrodynamic models. When building and adapting geological and hydrodynamic models of oil fields, especially those related to complex carbonate reservoirs, knowledge of both horizontal and vertical permeability (anisotropy parameter) is important. In practice, the vertical permeability in geological and hydrodynamic models is often assumed to be zero, although this is far from the case. Determining the vertical permeability (anisotropy parameter), its dynamics when changing reservoir and bottomhole pressures, and use in geological and hydrodynamic models is an important task that will improve the quality and accuracy of using digital models for calculating and predicting oil production.

The main aim of the study is to improve the geological and hydrodynamic model, taking into account the use of permeability anisotropy index.

Object: carbonate Famennian deposit of the Gagarinsky field.

Methods: processing of geological research data; use of the Tempest hydrodynamic simulator version 8.3.1 from Roxar.

The results. According to the method for determining the anisotropy parameter proposed in the article, 252 studies at production and injection wells in the Famennian deposit of the Gagarinsky field were carried out. For each lithofacial zone, the dependence of the permeability anisotropy index on the bottomhole pressure was constructed. For forecasting and evaluating the effectiveness of the applied geological and technical measures and technological indicators of development, the authors modified the geological and hydrodynamic model taking into account the dependencies obtained on the change in the anisotropy parameter. With the help of a modified hydrodynamic model, we managed to significantly improve the adaptation of both production and injection wells. Thus, it was possible to improve the quality and reliability of the digital model of the Famennian reservoir of the Gagarinsky field for calculating and forecasting oil production.

\section{Key words:}

Well testing, vertical permeability, horizontal permeability, lithologic-facies zones, modified hydrodynamic model.

\section{REFERENCES}

1. Vakhitova G.R., Galin N.N., Gumerova A.S. Analysis of the flooding of productive layers in the presence of spatial heterogeneity. Collection of scientific papers by SWORLD on the materials of the international scientific-practical conference, 2011, vol. 13, no. 2, pp. 80-90. In Rus.

2. Huafeng Sun, Sandra Vega, Guo Tao. Analysis of heterogeneity and permeability anisotropy in carbonate rock samples using digital rock physics. Journal of petroleum science and engineering, 2017, vol. 156, pp. 419-429.

3. Baikov V.A., Aksakov A.V., Borshchuk O.S. Mathematical modeling of fluid migration through a fluid seal along fractures. Oil industry, 2018, no. 5, pp. 48-51. In Rus.

4. Kadyrov R.I., Zakirov T.R. 2D fractal and multifractal analysis of voidness-pore space of carbonate reservoirs of oil. Oil Industry, 2016, no. 11, pp. 72-74. In Rus.

5. Martyushev D.A. Assessment of fracturing of carbonate reservoirs by probabilistic-statistical methods. Oil industry, 2014, no. 4, pp. 51-53. In Rus.

6. Abdullin R.N., Rakhmatullin A.R. An example of the practical application of information on fracturing according to the GIS complex and high-tech methods. Georesources, 2017, vol. 20, no. 3, pp. 261-266. In Rus.

7. Guerriero V., Mazzoli S., Iannace A., Vitale S., Strauss Ch. A permeability model for naturally fractured carbonate reservoir. Marine and petroleum geology, 2013, vol. 40, pp. 115-134.
8. Iktisanov V.A., Bobb I.F., Ganiev B.G. The study of the optimization of downhole pressure for fractured-porous reservoirs. Oil industry, 2017, no. 10, pp. 94-97. In Rus.

9. Henderson N., Pena L. Simulating effects of the permeability anisotropy on formation of viscous fingers during waterflood operations. Journal of petroleum science and engineering, 2017, vol. 153 , pp. 178-186.

10. Jackson R.R., Banerjee R. Application of reservoir simulation and history matching methods to MDT vertical interference testing and determination of permeability anisotropy. $8^{\text {th }}$ European Conference on the mathematics of oil recovery. Freiberg, Germany, 3-6 September 2002. pp. 775-794.

11. Khanipov M.N., Nasybullin A.V., Sattarov R.Z. Estimation of influence of heterogeneity of the reservoir on the efficiency of unsteady water flooding using geological and hydrodynamic modeling. Oil Industry, 2016, no. 7, pp. 30-32. In Rus.

12. Kudryashova D.A. Using probabilistic-statistical methods for determining the sources of irrigation of candidate wells for waterproofing works (using the example of a Visean facility in a field in the Perm Territory). Bulletin of the Perm National Research Polytechnic University. Geology. Oil and gas and mining, 2018, vol. 17, no. 1, pp. 26-36. In Rus.

13. Biao Li, Ron C.K. Wong, Sina Heidari. A modified Kozeny-Carman model for estimating anisotropic permeability of soft mudrocks. $M a$ rine and petroleum geology, 2018, vol. 98, pp. 356-368.

14. Yuling Tan, Zhejun Pan, Jishan Liu, Fubao Zhou, Asadul Haque. Experimental study of impact of anisotropy and heterogeneity on 
gas flow in coal. P. II: Permeability. Fuel, 2018, vol. 230, pp. 397-409.

15. Minory Sato, Takato Takemura, Manabu Takahashi. Development of the permeability anisotropy of submarine sedimentary rocks under true triaxial stresses. International journal of rock mechanics and mining sciences, 2018, vol. 108, pp. 118-127.

16. Noirot M., Massonnat G., Jourde H. On the use of Wireline Formation testing (WFT) data: 2 . Consequences of permeability anisotropy and heterogeneity on the WFT responses inferred flow modeling. Journal of petroleum science and engineering, 2015, vol. 133, pp. 776-784

17. Tsagan-Madzhiev T.N. Improving the reliability of determining the vertical permeability of the reservoir according to hydrodynamic studies. Gas industry, 2012, no. 5, pp. 19-23. In Rus.

18. Wen Zhang, Qin Wang. Permeability anisotropy and gas slippage of shales from the Sichuan Basin in South China. International journal of coal geology, 2018, vol. 194, pp. 22-32.

19. Cherepanov S.S., Martyushev D.A., Ponomareva I.N., Khizhnyak G.P. Evaluation of permeability anisotropy of carbonate reservoirs by pressure recovery curves. Oil industry, 2013, no. 4, pp. 60-61. In Rus.

20. Galkin V.I., Ponomareva I.N., Repina V.A. Investigation of the process of oil recovery in reservoirs of various types of emptiness using multidimensional statistical analysis. Perm National Research Polytechnic University Bulletin. Geology. Oil and gas and mining, 2016, vol. 15, no. 19, pp. 145-154. In Rus.

21. Shcherbenev A.V. Using probabilistic-statistical methods for dividing rocks into permeable and impermeable parts (using as an example terrigenous deposits of the Visean layer of the Sofinskoye deposit]. Perm National Research Polytechnic University Bulletin. Geology. Oil and gas and mining, 2017, vol. 16, no. 1, pp. 14-22. In Rus.

22. Begma D.S., Belkina V.A. Lithologic-facial features of the structure of Upper Jurassic deposits of the T deposit. Bulletin of the Tomsk Polytechnic University. Geo Assets engineering, 2017, vol. 328, no. 1, pp. 109-122. In Rus.

23. Khisamov R.S., Khabibrakhmanov A.G., Podavalov V.B., Kemaeva Yu.P., Mironova L.M. Features of the geological structure and prospects for the development of low-permeable carbonate reservoirs of the Podveryuskoe oil field. Oil industry, 2016, no. 11, pp. 84-87. In Rus.

24. Feng Ren, Guowei Ma, Guoyang Fu, Ke Zhang. Investigation of the permeability anisotropy of 2D fractured rock masses. Engineering geology, 2015, vol. 196, pp. 171-182.

25. Farrell N.J.C., Healy D., Taylor C.W. Anisotropy of permeability in faulted porous sandstones. Journal of structural geology, 2014, vol. 63, pp. 50-67.

26. Menezes F.F. Anisotropy of volume change and permeability evolution of hard sandstones under triaxial stress conditions. Journal of petroleum science and engineering, 2019, vol. 174, pp. 921-939.

27. Heap M., Reuschle T., Baud P., Renard F., Lezzi G. The permeability of styolite-bearing limestone. Journal of structural geology, 2018, vol. 116, pp. 81-93.

28. Sayakhutdinov A.I., Kondratieva N.R., Gallyamova D.Ch., Karachurina E.V., Bulatova E.S. Method of complex carbonate reservoir simulation of fractured reservoirs on the example of Mancharovskoe deposit. Oil Industry, 2014, no. 2, pp. 114-115. In Rus.

29. Cherepanov S.S., Chumakov G.N., Galkin S.V. Opportunities of accounting fractured reservoirs in geological and hydrodynamic modeling of development of reservoir with water flooding layers. Oilfield business, 2016, no. 8, pp. 5-8. In Rus.

30. Schipanov A.A. Modification of relative phase permeabilities as one of the approaches to the consideration of reservoir fracturing in hydrodynamic modeling. Geology, geophysics and development of oil and gas fields, 2002, no. 8, pp. 60-66. In Rus.

31. Kashnikov Yu.A., Ashikhmin S.G., Kukhtinsky A.E., Shustov D.V. On the relationship of fracture toughness coefficients and geophysical characteristics of rocks of hydrocarbon deposits. Journal of Mining Institute, 2020, vol. 241, pp. 83-90. In Rus.

32. Abbasov E.M., Agaeva N.A., Kerimova Sh.A. Integral modeling of gas well operation considering the deformability of the reservoir SOCAR Proceedings, 2019, no. 2, pp. 45-52. In Rus.

Received: 28 August 2019.

\section{Information about the authors}

Alexander G. Mengaliev, $2^{\text {nd }}$ category engineer, LLC «LUKOIL-Engineering» «PermNIPIneft» in Perm.

Dmitriy A. Martyushev, Cand. Sc., assistant professor, Perm National Research Polytechnic University. 